\title{
ANÁLISE FÍSICA DO SOLO DE VÁRZEA NAS MARGENS DO RIO GUAMÁ NA AMAZÔNIA ORIENTAL
}

Eliana Costa Seabra - elianacosta0494@gmail.com

Universidade Federal Rural da Amazônia

Jamilly Rocha de Araújo - millyrocha@yahoo.com.br

Universidade Federal Rural da Amazônia

Diego Costa Chaves-dieghoves@gmail.com

Universidade Federal Rural da Amazônia

Juliane Silva Ferreira -juliane.s.f@hotmail.com

Universidade Federal Rural da Amazônia

Nicele Bruna Coelho Aguiar - nicelecoelho@outlook.com

Universidade Federal Rural da Amazônia

Aline de Castro Vitelli - alinecvitelli@gmail.com

Universidade Federal Rural da Amazônia

Stefane de Cassia Reis do Vale- stefane128@ hotmail.com

Universidade Federal Rural da Amazônia 


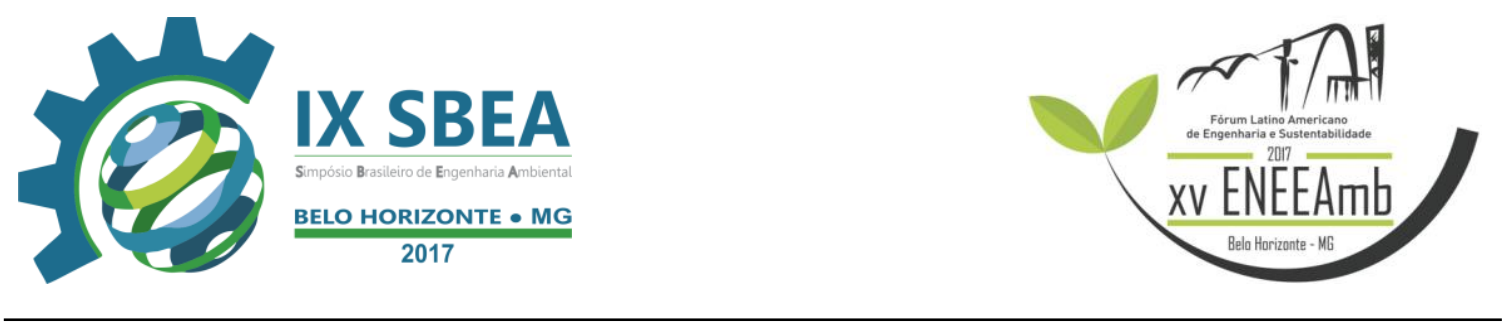

\section{RESUMO}

A necessidade de estudar as propriedades físicas dos solos de várzea, nas margens do rio Guamá no campus da Universidade Federal Rural da Amazônia (UFRA) apresenta uma rica biodiversidade, assim como as poucas informações disponíveis sobre as alterações nas características físicas. este trabalho tem como objetivo avaliar os impactos causados através de analises físicas do solo de várzea localizado nas margens do Rio Guamá, na Amazônia Oriental. Os solos de Várzea são solos heterogêneos, com desenvolvimento iniciado a partir da deposição de diferentes composições granulométricas, mineralógicas e orgânicas, são ricos em minerais, provenientes de rochas calcárias da Cordilheira dos Andes (Moreira et al. 2005). O objetivo deste trabalho foi avaliar os impactos causados através de analises físicas do solo de várzea localizado nas margens do Rio Guamá, na Amazônia Oriental. Foram coletadas amostras de solos na área de várzea, em três pontos e em duas profundidades 0-5 e 5-10. As análises foram feitas no laboratório de Física do Solo (Granulometria e Densidade), no Departamento de Ciência do Solo da UFRA, utilizando a metodologia da Embrapa. Cnps(1997). A partir das análises, pode-se concluir que o solo do tipo Franco-argilosiltosa expressas por valores elevados, estabelecem riscos e índices de vulnerabilidade à erosão pela ação da água. Estas áreas são denominadas desta forma por constituir-se de terrenos baixos e mais ou menos planos, se encontram junto às margens de rios e lagos.

Palavras-chave: Amazônia, Solos, Várzea. 


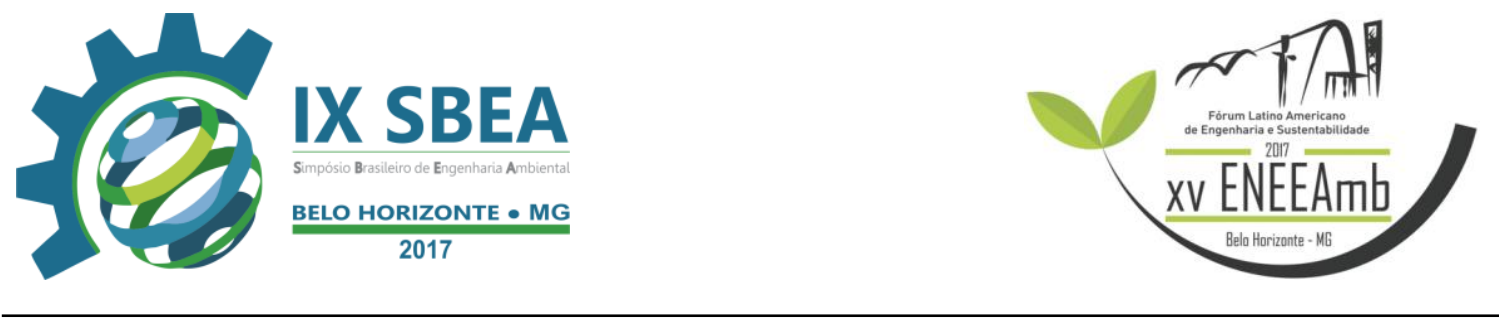

\section{INTRODUÇÃO/OBJETIVO}

A área de estudo fica localizada em Belém (PA), nas margens do rio Guamá no campus da Universidade Federal Rural da Amazônia (UFRA), na floresta típica de Várzea. Segundo Koppen, o clima da região é do tipo Afi que corresponde a climas tropicais úmidos. A formação das várzeas deve-se a um processo de adição recente de sedimentos ocasionado pelo regime das águas, onde estes materiais vão se depositando por ordem de peso e tamanho.

As partículas maiores e mais pesadas se depositam na faixa próxima as margens (várzea alta), as mais finas sedimentam logo em seguida (várzea baixa) e as partículas finíssimas são transportadas para o interior (igapó), sendo que estas diferenças refletem as propriedades do solo (LIMA; TOURINHO,1996).

Os solos de Várzea são solos heterogêneos, com desenvolvimento iniciado a partir da deposição de diferentes composições granulométricas, mineralógicas e orgânicas, são ricos em minerais, provenientes de rochas calcárias da Cordilheira dos Andes (Moreira et al. 2005).

Geologicamente, as várzeas podem ser divididas naquelas formadas no Pleistoceno, (cerca de 18.000 anos) e em outras formadas no Holoceno (cerca de 5.000 anos), ambas formadas pelas flutuações do nível do mar e dos rios, devido às glaciações nestes períodos. Os ecossistemas de várzea na bacia Amazônica representam uma área de aproximadamente 200.000 km2 (Junk, 1983; Furch, 2000). As várzeas Holocênicas são mais jovens e possuem os solos mais férteis de toda a Amazônia, dada à deposição periódica de sedimentos resultante das inundações anuais, formando regularmente uma camada nova de solo, proveniente dos Andes (Irion, 1984).

Do ponto de vista pedológico, os solos de várzeas apresentam pouco ou nenhum desenvolvimento do perfil e estão representados pelas ordens dos Neossolos Flúvicos, Gleissolos, Organossolos e Vertissolos, podendo ser eutróficos ou distróficos dependendo de sua localização topográfica, e da qualidade das águas e dos sedimentos que os inundam (Vitória et al., 1989; Embrapa, 1999).

Considerando a dimensão física territorial ocupada pelas várzeas na Amazônia, aproximadamente 25 milhões de hectares de terras irrigáveis (RODRIGUES; 
OLIVEIRA, 1996), com rica biodiversidade, assim como as poucas informações disponíveis sobre as alterações nas características físicas, este trabalho tem como objetivo avaliar os impactos causados através de analises físicas do solo de várzea localizado nas margens do Rio Guamá, na Amazônia Oriental.

\section{METODOLOGIA}

A área de estudo fica localizada em Belém (PA), nas margens do rio Guamá no campus da Universidade Federal Rural da Amazônia (UFRA), na floresta típica de Várzea (Mapa 1). Segundo Koppen, o clima da região é do tipo Afi que corresponde a climas tropicais úmidos. A formação das várzeas deve-se a um processo de adição recente de sedimentos ocasionado pelo regime das águas, onde estes materiais vão se depositando por ordem de peso e tamanho.

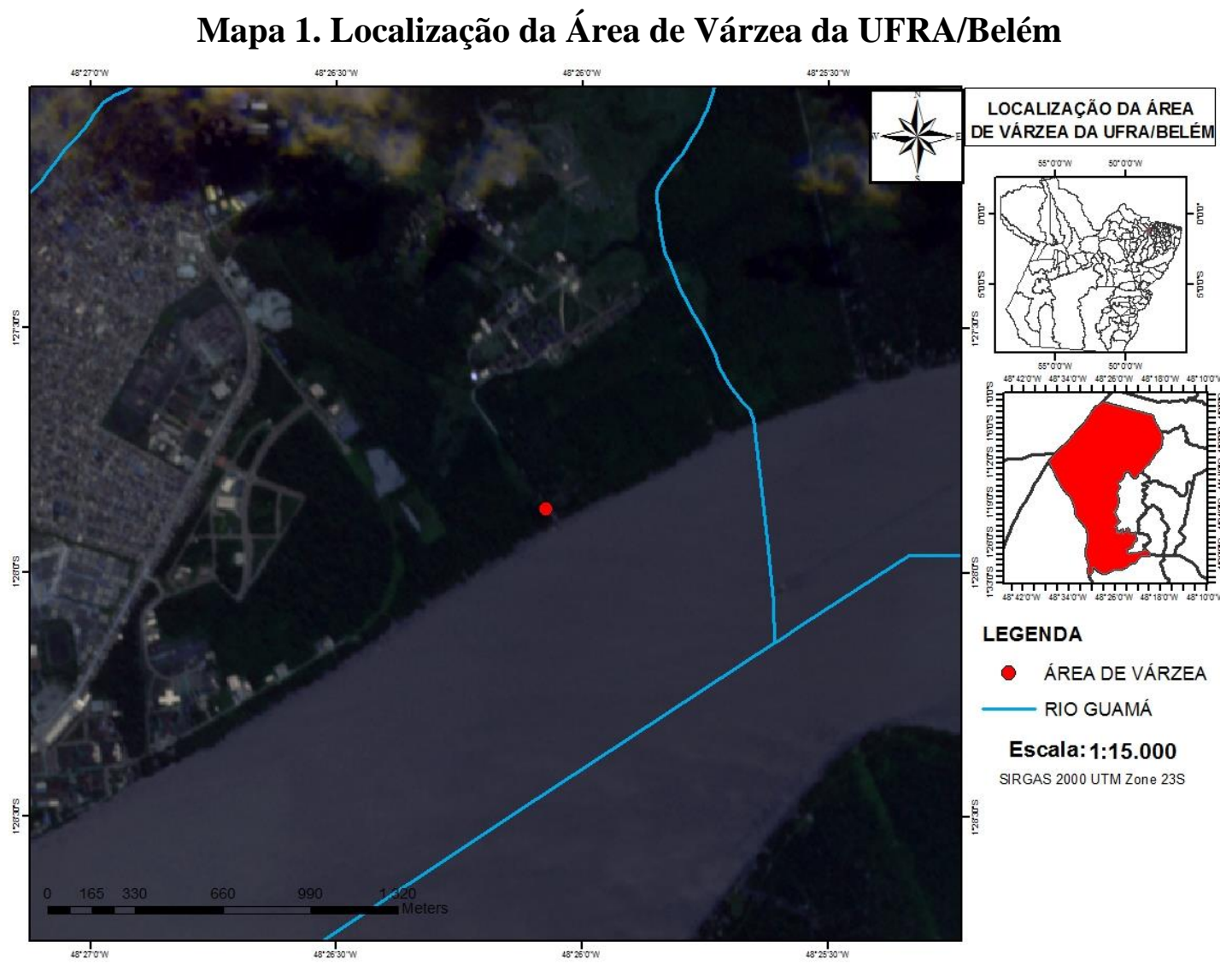

Fonte: Autor 


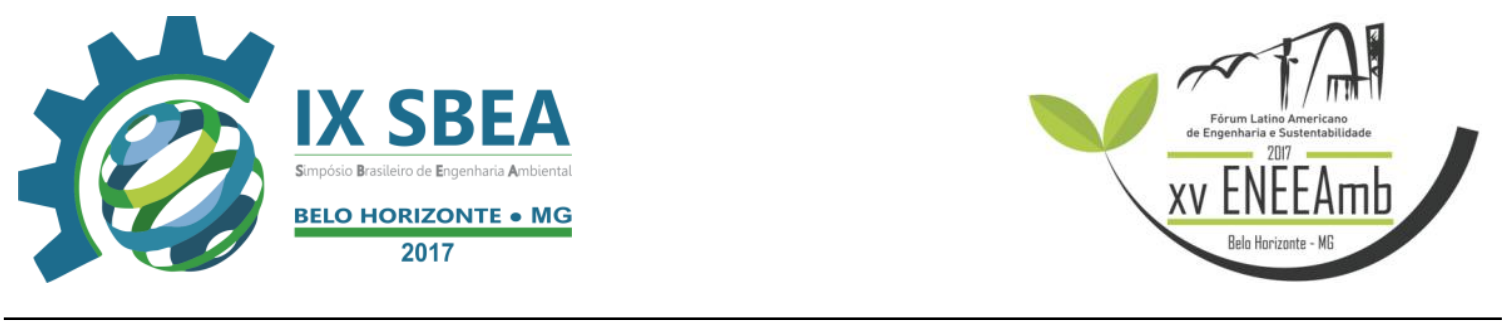

Foram coletadas amostras de solos na área de várzea, em três pontos e em duas profundidades 0-5 e 5-10, foram armazenadas em sacolas plásticas e identificadas. Em seguida foram colocadas para secar a temperatura ambiente durante três dias. Após de secas ao ar, as amostras deformadas foram emassadas e passadas em peneiras com malha $2 \mathrm{~mm}$, para posteriormente serem realizadas as analises químicas, físicas e biológicas. As análises foram feitas no laboratório de Física do Solo(Granulometria e Densidade), no Departamento de Ciência do Solo da UFRA, utilizando a metodologia da Embrapa. Cnps(1997).

Para a análise granulométrica foi pesado uma pequena porção de TFSA (10g para solo argiloso, $20 \mathrm{~g}$ para franco, $40 \mathrm{~g}$ para franco arenoso e areia frannca e $80 \mathrm{~g}$ para arenoso), transferiu-se a amostra para o recipiente do agiador $400 \mathrm{ml}$ de água destilada e $10 \mathrm{ml}$ de solução de $\mathrm{NaOH}$ (dispersante) e agitou-se por $16 \mathrm{~h}$ em um agitador horizontal com $120 \mathrm{rpm}$.

Despejou-se a suspensão por uma peneira de $20 \mathrm{~cm}$ de diâmetro e malha de

0,053, colocada sobre um funil apoiado em um suporte, em baixo uma proveta de $1000 \mathrm{ml}$ ou um cilindro de sedimentação. Em seguida a peneira foi lavada com agua destilada, o sedimento restante foi colocado em um Becker de peso conhecido, e inserido em uma estufa à $105^{\circ} \mathrm{C}$. Depois de retirada da estufa foi pesado a fração areia.

Para a determinação da fração argila, foi preparada uma prova em branco, adicionando $10 \mathrm{ml}$ de solução de $\mathrm{NaOH}$ em uma proveta de $1000 \mathrm{ml}$ alcançando o volume de 11 com água destilada, deixando o solo e aprova em branco em suspensão por uma hora, agitando a suspensão com um bastão por 30s, anotando o tempo de conclusão e a temperatura. Após o termino de a suspensão transferir para o Becker com peso conhecida a porção proveniente da lavagem da pipeta, colocar o Becker em uma estufa à $105^{\circ} \mathrm{C}$ por $24 \mathrm{~h}$, e por fim pesar e identificar a argila e o resíduo da prova em branco.

A densidade do solo (Ds) foi mensurada pelo método do anel volumétrico, que se baseia no uso de anel de bordas cortantes com volume conhecido, esse método é considerado como método padrão de amostragem para a avaliação da densidade do solo, o qual consiste na amostragem do solo com estrutura indeformada num anel (cilindro metálico) de volume conhecido (EMBRAPA, 1997). 
O solo de dentro do anel foi pesado e seco em estufa a $105^{\circ} \mathrm{C}$. Após $48 \mathrm{~h}$, o solo seco foi retirado e pesado, onde determinou-se a Ds(Densidade do Solo) através da Equação 1:

$$
D s=m / V c
$$

Onde: Ds $=$ Densidade do solo $\left(\mathrm{g} \mathrm{cm}^{3}\right) ; \mathrm{m}=$ massa de solo seco $(\mathrm{g}) ; \mathrm{Vc}=$ volume do anel (cm-3).

\section{RESULTADOS E DISCUSSÃO}

Os dados obtidos através das analises de granulometria (Tabela 1) mostraram que a textura dominante identificada é Franco-argilo-siltosa nas duas profundidades, com a argila variando entre os $32,65 \%$ e a areia variando entre $38,62 \%$ de acordo com o triângulo textural(Figura 1).

Tabela 1. Resultados das Análises de Físicas do Solo de Várzea.

\begin{tabular}{|l|l|l|l|}
\hline \multirow{2}{*}{ Pontos } & \multicolumn{2}{|c|}{ Aranulometria (\%) } & Densidade (g/m $\left.{ }^{3}\right)$ \\
& \multicolumn{1}{|c|}{ Areia } & & 1,37 \\
\hline P1(0-5) & & $32,06 \%$ & 1,35 \\
\hline P1(5-10) & $33,83 \%$ & & \\
\hline P2(0-5) & & & 1,40 \\
\hline P2(5-10) & $38,62 \%$ & $35,48 \%$ & 1,42 \\
\hline P3(0-5) & & & \\
\hline P3(5-10) & & & \\
\hline
\end{tabular}

Os dados obtidos de densidade (Tabela 1) demostraram que a densidade do solo é afetada naturalmente pela textura e teor de matéria orgânica do solo e antropicamente pelos sistemas de manejo e pelo grau de compactação atingido. Solos compactados caracterizam-se pelo aumento da densidade e redução na porosidade, principalmente 


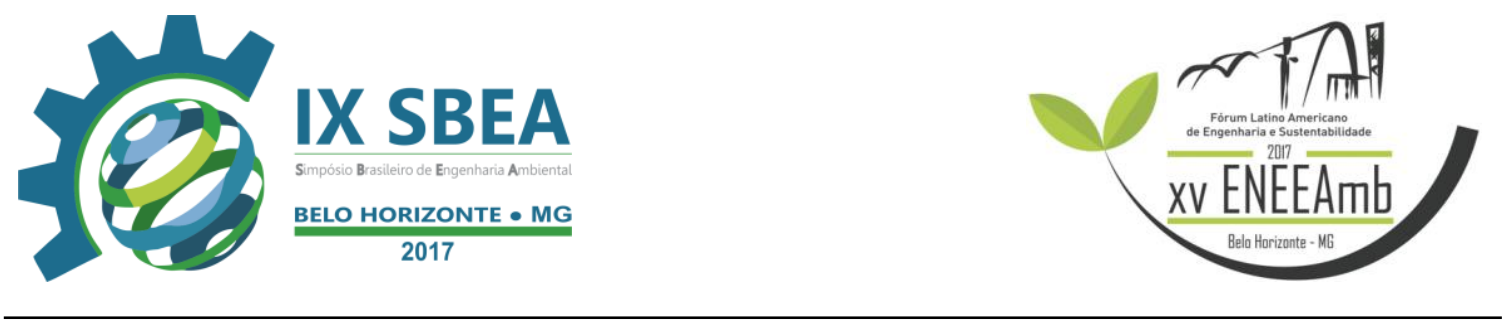

nos macroporos. A densidade do solo pode se tornar critica com a flutuação nos teores de umidade do solo, de forma que com baixos teores de umidade a resistência à penetração ou a disponibilidade de água tornam-se limitantes, e em condições de alta umidade a aeração do solo passa a ser limitante (TOMÉ, 1997).

Silva et al. (1998), estabeleceram valores críticos de densidade do solo, propuseram como sendo de 1,45 g cm-3 para solos com horizonte de textura argilosa (mais de $55 \%$ de argila), 1,55 g cm-3 para solos com horizonte de textura média (argila entre 20 e $55 \%$ ) e de $1,65 \mathrm{~g} \mathrm{~cm}-3$ para solos com textura arenosa (menos de $20 \%$ de argila).Os valores de densidade do solo (Ds) encontrados nos dois pontos e em duas profundidades estão de acordo com os definidos por Brady (1989) de 1,00 a 1,60 g cm para solos com textura franco-siltoso, argilo-siltoso e solos argilosos. Sendo que neste trabalho ficou em torno de 1,35 a $1,42 \mathrm{~g} \mathrm{~cm}^{3}$.

\section{CONCLUSÕES/RECOMENDAÇÕES}

Este trabalho analisou aspectos relacionados às propriedades físicas, localizados em áreas de várzea no Rio Guamá na Amazônia Oriental. A partir das análises, pode-se concluir que o solo do tipo Franco-argilo-siltosa expressas por valores elevados, estabelecem riscos e índices de vulnerabilidade à erosão pela ação da água. Perfis saturados de água por capilaridade e texturas siltosas, favorecem o deslizamento e e desmoronamentos.

As áreas de várzeas possuem características físicas limitantes ou maior susceptibilidade a degradação. A área de várzea, onde foram realizadas as coletas para analises em laboratório, apresenta características de planície de inundação. Estas áreas são denominadas desta forma por constituir-se de terrenos baixos e mais ou menos planos, se encontram junto às margens de rios e lagos. 


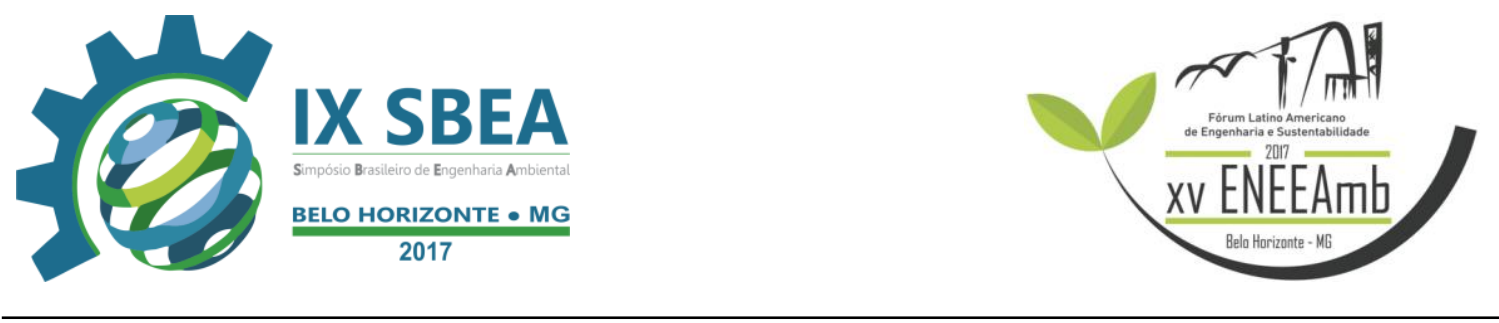

\section{REFERÊNCIAS BIBLIOGRÁFICAS}

ALFAIA, Sonia Sena; SOUZA, Luiz Augusto Gomes; FAJARDO, Juan Daniel Villacis. Características químicas de solos de várzeas sob diferentes sistemas de uso da terra, na calha dos rios baixo Solimões e médio Amazonas. Instituto Nacional de Pesquisas da Amazônia /INPA. Acta Amazônica. vol.39. Manaus/ AM. 2009.

BRADY, N.C. Natureza e propriedades dos solos. 7. ed. Rio de Janeiro: F. Bastos, 1989. 898p.

COCHRANE, T.T.; SANCHEZ, L.G.; AZEVEDO, L.G. de; PORRAS, J.A.; GARVEL, C.L. A terra na América tropical. Cali: CIAT/EMBRAPA-CPAC, 1985

DA SILVA, Cláudio Ricardo; DE SOUZA, Zigomar Menezes. Eficiência do uso de nutrientes em solos ácidos: manejo de nutrientes e uso pelas plantas. 1998.

EMBRAPA. Centro Nacional de Pesquisa de Solos. Manual de Métodos de Análise de Solo. 2.ed. Rio de Janeiro, 1997(Embrapa-CNPS. Documentos,1).

FERREIRA, W. de A.; MODESTO JÚNIO, M. de S.;BOTELHO, S. M.; MASCARENHAS, R.E.B. Efeito da inundação sobre as propriedades de um glei pouco húmico de várzea do rio Guamá, nos municipios de Belém e Santa Isabel, PA. Belém: EMBRAPA-CPATU, 1998.

Furch, K. 1997. "Chemistry of várzea and igapó soils and nutrient inventory of their floodplains forests", in W. J. Junk (Ed.), The Central Amazon floodplain: ecology of a pulsing system. Ecological Studies, Springer, Berlim, 126: 47-67.

Furch, K. 2000. Chemistry and bioelement inventory of contrasting Amazonian forest soils. In: Junk, W. J.; Ohly, J. J.; Piedade, M. T. F.; Soares, M. G. M. (Eds.). The Central Amazon Floodplain: Actual Use and Options for a Sustainable Management. Backhuys Publishers, Leiden, The Netherlands, p. 109-128.

Irion, G., 1984 Sedimentation and Sediments of Amazon rivers and evolution of the Amazon landscape since pleocine time. Dordrecht, Dr. W Junk Publishers, p. 201-203. Junk, W.J. 1983. As águas da região Amazônica. In: E. SALATI, et al (eds). Amazônia: Desenvolvimento, integração e ecologia. Editora Brasiliense/CNPq. P. 45-100.

KOPPEN, W.; GEIGER,R. Klimate der Erde. Gotha: Verlag Justus Perthes. 1928. Wall-map $150 \mathrm{~cm} \times 200 \mathrm{~cm}$.

LIMA, Rubens Rodrigues; TOURINHO, Manoel Malheiros. Várzeas do rio Pará; principais características e possibilidades agropecuárias. Belém: FCAP, 1996. 124p.

LOPES, A.S. COX, F.R.AA. A survey of the fertility staatus of surface soiils under cerrado vegetattion in Brazzzil. Soil Science Sociiety of American Journaal, Madison, v.41, p742-746, 1977. 


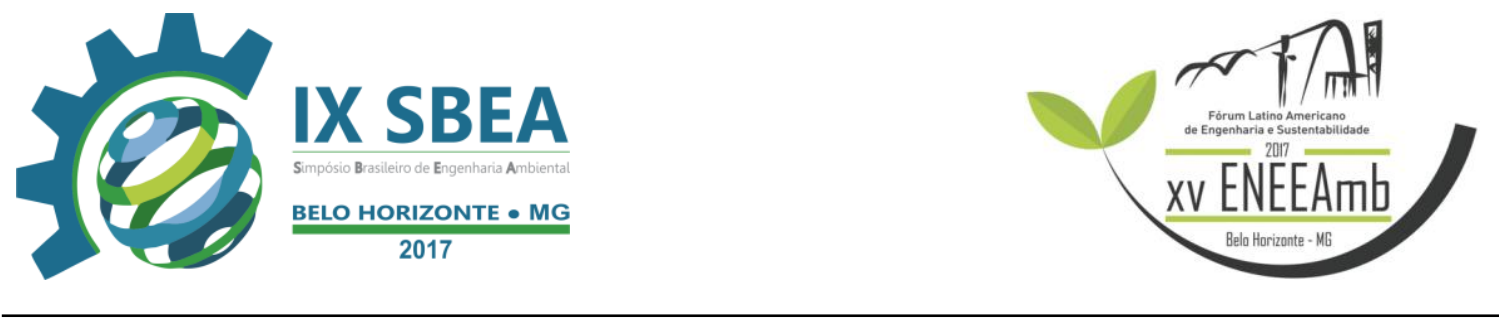

Magalhães, R. C. Gomes, R. C. M. Mineralogia e química de solo de várzea e suas susceptibilidades no processo de terras caídas na comunidade do Divino Espírito SantoAM. Soc. \& Nat., Uberlândia, 2013, pag. 609-621

MOREIRA, A.; CASTRO, C.; ALFAIA, S. S.; MALAVOLTA, E. 2005. Fertilidade dos solos da Amazônia. In: Palestra apresentada no XXX Congresso Brasileiro de Ciência do Solo. Recife, PE. p. 1 - 27.

NASCIMENTO, Paulo César; BAYER, Cimélio. Sistemas de Manejo e a Matéria Orgânica de Solo de Várzea Com Cultivo de Arroz. R. Bras. Ci. Solo, 33: 1821-1827, 2009.

PIMENTEL, Gladys Beatriz Martinez. Sistemas de manejo de um Gley Pouco Húmico do Médio Amazonas Paraense Monte-Alegre-Pará. 1991. 70p. Dissertação (Mestrado)Faculdade de Ciências Agrárias do Pará, Belém, 1991.

SILVA, F. C.; EIRA, P. A.; BARRETO, W. O.; PÉRES, D. V.; SILVA, C. A. Análises Químicas para Avaliação da Fertilidade do Solo (Métodos usados na Embrapa Solos), EMPRAPA, 1998.

Victoria, R. L.; Martinelli, L. A.; Richey, J.E.; Forsberg, B.R. 1989 Spatial and temporal variations in soil chemistry on the Amazon Floodplain. Geojournal, 19(1): 4552.

Tomé Jr, J. B. 1997. Manual para Interpretação de Análise de solo. Agropecuária Ltda, Guaíba-RS, 247 p.ROMANO, Giovanni. Imagens da juventude na era moderna. In: LEVI, G.; SCHMIDT,J. (Org). História dos jovens 2. São Paulo: Companhia de Letras, 1996. P.7-16. 